\title{
Effect of Antibiotic Pretreatment on Cerebrospinal Fluid Profiles of Children with Acute Bacterial Meningitis
}

\author{
Adhikari $S,{ }^{1 *}$ Gauchan $E,{ }^{1} B K G,{ }^{1}$ Rao $K S^{1}$ \\ ${ }^{1}$ Department of Paediatrics, Manipal College of Medical Sciences, Pokhara, Nepal
}

\begin{abstract}
*Corresponding Author:
Dr. Sudhir Adhikari,

Lecturer, Department of Pediatrics,

Manipal College of Medical Sciences, Pokhara, Nepal

Email-sudhiradhikari99@gmail.com

\section{Citation}

Adhikari S, Gauchan E, BK G, Rao KS. Effect of Antibiotic Pretreatment on Cerebrospinal Fluid Profiles of Children with Acute Bacterial Meningitis. Nepal Journal of Medical sciences 2013;2(2):135-9.
\end{abstract}

\section{Background:}

Acute bacterial meningitis (ABM) is an important disease of early childhood with high case fatality and risk of neurologic handicaps. ${ }^{1-3}$ The community incidence of ABM fluid

\begin{abstract}
Background: Analysis of cerebrospinal fluid is gold standard for diagnosis of meningitis. There is considerable difficulty in interpreting laboratory finding after prior antibiotic therapy. This study was conducted to evaluate the effect of intravenous antibiotic administration before lumbar puncture on cerebrospinal fluid profiles in children with bacterial meningitis.
\end{abstract}

Methods: A hospital based retrospective study carried out using the data retrieved from the medical record department of Manipal Teaching Hospital Pokhara, Nepal; from 1st July 2006 to 31st July 2011. Clinical findings and relevant investigations were entered in a predesigned proforma. Patients were divided in two different groups as bacterial meningitis with and without prior intravenous antibiotic therapy. Various laboratory parameters including CSF were compared between these two groups using the statistical software, SPSS version 18.0.

Results: A total of 114 children were included in this study among which $49(43 \%)$ children had received intravenous antibiotics before lumbar

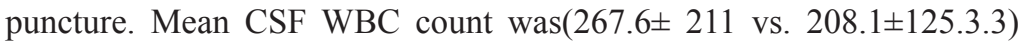
and protein level $(114.1 \pm 65.9$ vs. $98.3 \pm 37.7 \mathrm{mg} / \mathrm{dl})$ in untreated vs. pretreated groups respectively. Neutrophil percentage was decreased $(57.1 \pm 28.1$ vs. $72.9 \pm 18.9)$ with higher CSF sugar level $(43.3 \pm 11.8$ vs. $51.2 \pm 13.2)$ after prior antibiotics therapy $(\mathrm{p}<0.001)$.

Conclusion: Antibiotic pretreatment was associated with higher cerebrospinal fluid glucose levels with decreased neutrophils and increased lymphocytes. Pretreatment did not modify total cerebrospinal fluid white blood cell count and cerebrospinal fluid protein levels.

Keywords: Antibiotic pretreatment; bacterial meningitis; cerebrospinal

in Nepal is not known. The exact etiological diagnosis is often not possible, because of poor culture facilities., ${ }^{4,5}$ Demonstration of microorganism in culture is considered gold standard for diagnosis of meningitis. Administration of 
antibiotics to children before the performance of diagnostic lumbar punctures increases the number of false negative cerebrospinal fluid (CSF) bacterial culture results. ${ }^{1,2}$ Isolation of organism in blood culture and demonstration of antigens with rapid diagnostic test can aid diagnosis in culture and gram stain negative cases and help in diagnosis after antibiotic pretreatment. When microbial etiology cannot be established especially in poor resource countries with limited laboratory facilities, diagnosis need to be established with CSF cytology and biochemistry. Vaccines against haemophilus influenzae b was recently introduced and against pneumococci is administrated in limited children from developing countries like Nepal. ${ }^{6}$

The effects of prior antibiotic therapy on CSF cellular and chemical profiles were studied previously but remain a matter of controversy. CSF obtained from children with bacterial meningitis, after the initiation of antibiotics, may be negative on Gram stain and culture. ${ }^{7,8}$ Pleocytosis with a predominance of neutrophils, elevated protein level, and a reduced concentration of CSF glucose usually persist for several days after the administration of appropriate intravenous antibiotics. ${ }^{9}$ Some previous work suggested that antibiotic pretreatment does not affect or has only a small influence on CSF white blood cell (WBC) profiles in patients with bacterial meningitis while others found significant alteration in CSF profile. ${ }^{10-13}$

Clinical prediction for the identification of bacterial meningitis combined with clinical and laboratory parameters have been developed to estimate the risk of bacterial meningitis. Most of these scoring systems are done with positive culture on CSF and in the absence of prior antibiotic therapy. ${ }^{14}$ Accuracy of the bacterial meningitis score in children with pretreated bacterial meningitis and without positive culture is untested. Some studies indicate biomarker in serum and CSF likeC-reactive protein (CRP), Procalcitonin, Lactate dehydrogenase (LDH), Adenosine deaminase (ADA) might help to differentiate between bacterial meningitis from aseptic meningitis. ${ }^{15}$ These investigations have limited availability and need further evidence.

Empirical antibiotic therapy without full diagnostic evaluation is quite rampant in developing nations like ours. This often leads to confusion in interpreting CSF profile of patients with suspected meningitis. So we conducted this study to see the effect of antibiotic pretreatment on CSF profile and other parameters in children with bacterial meningitis.

\section{Methods:}

We reviewed a retrospective data of children with diagnosis of acute pyogenic meningitis from department of Pediatrics, Manipal Teaching Hospital, Pokhara, Nepal. Children of 1 month to 15 years of age discharged during the period

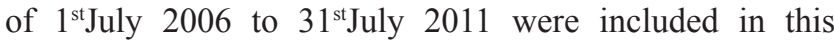
study. The medical records of all potential study children were reviewed to determine the exposure of intravenous antibiotic pretreatment and its timing with lumbar puncture, clinical features and laboratory results. Patients with head injury or recent neurosurgery (within 1 month), CSF shunts, sick children requiring ventilatory support and immunocompromised children were excluded because the etiological agents and the inflammatory response may be different from those in a previously healthy population.

Subjects were then classified into probable and confirmed cases of meningitis. Probable bacterial meningitis was defined as a case with no bacteria identified in the CSF but with leukocytosis of greater than or equal to 100 white blood cell $/ \mathrm{mm}^{3}$ (PMNs) representing $>50 \%$, the CSF glucose $<2 / 3$ rd of blood sugar level and CSF protein 100-500 mg/ dl. For children with prior antibiotic therapy before CSF analysis and CSF leukocyte count 5-10,000 with PMNs or lymphocytes predominating, protein $100-500 \mathrm{mg} / \mathrm{dl}$, CSF sugar normal or decreased were considered probable bacterial meningitis. ${ }^{8}$ A confirmed case of meningitis was defined as one of the following: Bacterial isolation from CSF or blood culture or a positive Gram Stain with no bacterial growth. We included the patients with probable bacterial meningitis in the bacterial meningitis group for the subsequent analysis.

Children with acute bacterial meningitis were divided into two groups; with or without prior antibiotic therapy. Patients with missing information regarding timing and duration of antibiotic pretreatment were not included in the study.

We categorized a patient as having pretreated bacterial meningitis if a patient with bacterial meningitis or probable bacterial meningitis was given a dose of intravenous antibiotic within 72 hours and last dose $>4$ hours before the performance of the lumbar puncture. Clinical features and laboratory investigations including complete blood count, blood sugar, serum $\mathrm{C}$ reactive protein (CRP) and blood culture were recorded. All data were first recorded in a predesigned proforma and variables of interest were compared between these two groups using unpaired $\mathrm{T}$ test. All analyses were done using Statistical software SPSS version 18.0 . 


\section{Results:}

A total of 129 patients with acute pyogenic meningitis were admitted during the study period of July 2006 to July 2011. Fifteen cases which lacked data about antibiotic pretreatment were excluded from the study. Remaining114 patients with bacterial meningitis and probable bacterial meningitis were included in the bacterial meningitis group.

Most of the children with acute bacterial meningitis were less than 1 year of age $42(36.8 \%)$. The children with pretreated bacterial meningitis were slightly younger than those with no pretreated bacterial meningitis. There were 62(54.4\%) males and 52(45.6\%) females. Of the 114 study patients, $65(57 \%)$ had not received prior antibiotic therapy while 49 $(43 \%)$ had pretreatment as shown in table 1.

Table 1: Age groups Distribution of acute bacterial meningitis

\begin{tabular}{llll}
\hline Age (years) & $\begin{array}{c}\text { Without } \\
\text { prior } \\
\text { antibiotics }\end{array}$ & $\begin{array}{c}\text { With prior } \\
\text { antibiotics }\end{array}$ & $\begin{array}{r}\text { Total } \\
\text { N(\%) }\end{array}$ \\
\hline$\leq 1$ & $22(52.4)$ & $20(47.6)$ & $42(36.8)$ \\
$1-5$ & $20(60.6)$ & $13(39.4)$ & $33(28.9)$ \\
$>5$ & $23(59.0)$ & $16(41.0)$ & $39(34.2)$ \\
Total & $65(57.0)$ & $49(43.0)$ & $114(100)$ \\
\hline
\end{tabular}

Fever was most common presenting feature 113(99.1\%) followed by lethargy, vomiting, positive meningeal sign, convulsions, altered sensorium and headache. Meningeal signs were recorded more commonly in children without antibiotic treatment $35(53 \%)$ compared with pretreated group 15(37\%). Only 6(5.3\%) children had rash and other features including photophobia, dizziness were present in $20(17.5 \%)$ of children (Table-2).

Table 2: Clinical features in acute bacterial meningitis

\begin{tabular}{llll}
\hline & $\begin{array}{c}\text { Without } \\
\text { antibiotics } \\
\mathbf{n}(\%)\end{array}$ & $\begin{array}{c}\text { With } \\
\text { antibiotics } \\
\mathbf{n}(\mathbf{\%})\end{array}$ & $\begin{array}{c}\text { Total } \\
\mathbf{n}(\mathbf{\%})\end{array}$ \\
\hline Fever & $65(100)$ & $48(98)$ & $113(99.1)$ \\
lethargy & $60(92)$ & $44(89.8)$ & $104(91.2)$ \\
Vomiting & $62(96)$ & $40(81.6)$ & $102(89.5)$ \\
Meningeal sign & $35(53)$ & $15(37)$ & $50(43.9)$ \\
Convulsions & $21(32.3)$ & $18(30.5)$ & $39(34.2)$ \\
Altered sensorium & $21(32.3)$ & $14(23.7)$ & $35(30.7)$ \\
Headache & $20(30.7)$ & $10(17)$ & $30(26.3)$ \\
Rash & $4(9.2)$ & $2(3.4)$ & $6(5.3)$ \\
Others & $12(18.4)$ & $8(13.6)$ & $20(17.5)$ \\
\hline
\end{tabular}

Children with acute bacterial meningitis in both groups showed leukocytosis with neutrophil predominance. Serum CRP level was higher in children without prior antibiotic therapy compared to pretreated children, 29.6 and $22.5 \mathrm{mg} /$ dl respectively. Serum sodium level was in lower limit in children of both the groups136 $( \pm 5.2)$ vs136 $( \pm 5.2) \mathrm{meq} /$ L(Table-3).

Table 3: Laboratory investigations in children with bacterial meningitis

\begin{tabular}{llll}
\hline & $\begin{array}{c}\text { Without prior } \\
\text { antibiotics } \\
\text { Mean } \pm \text { SD }\end{array}$ & $\begin{array}{l}\text { With prior } \\
\text { antibiotics } \\
\text { Mean } \pm \text { SD }\end{array}$ & P value \\
\hline Hemoglobin $\mathrm{mg} / \mathrm{dl}$ & $10.7(1.6)$ & $11.1(1.7)$ & 0.256 \\
TLC / $\mu \mathrm{L}$ & $12,400(4924)$ & $11,400(5159)$ & 0.283 \\
PMNS(\%) & $74.7(15.2)$ & $73(19.4)$ & 0.599 \\
Lymphocytes (\%) & $25.3(15.2)$ & $27(19.4)$ & 0.599 \\
CRP (mg/dl) & $29.6(30.0)$ & $22.5(19.0)$ & 0.151 \\
$\begin{array}{l}\text { Blood culture } \\
\text { positivity) }\end{array}$ & $4(6.1 \%)$ & $2(4.1 \%)$ & 0.627 \\
$\begin{array}{l}\text { Serum sodium } \\
\text { (meq/L) }\end{array}$ & $136(5.2)$ & $137.3(6.6)$ & 0.245 \\
\hline
\end{tabular}

TLC;Tolal leucocytes count, PMNS- polymorphs,

The CSF total WBC count was 267.6 \pm 211.3 and $208.1 \pm 125.3$ in those without and with prior antibiotics therapy. Children with pretreated bacterial meningitis had decreased neutrophil count $(57.1 \pm 28.1 \%)$ and increased lymphocytes $(44.4 \pm 29.1 \%)$ compared to those without prior therapy $(\mathrm{p}=0.001)$. CSF sugar was lower $43.3 \pm 11.8$ $\mathrm{mg} / \mathrm{dl}$ without prior treatment than those with pretreatment $51.2 \pm 13.2 \mathrm{mg} / \mathrm{dl}(\mathrm{p}=0.001)$.Children in the both groups had increased mean CSF protein level $(256.90 \pm 203.61 \mathrm{mg} / \mathrm{dl}$ and $\mathrm{mg} / \mathrm{dl}$ )(Table-4).

Table 4: Cerebrospinal Fluid Profiles of Children with Acute Pyogenic Meningitis

\begin{tabular}{lllll}
\hline & $\begin{array}{c}\text { Without prior } \\
\text { antibiotic } \\
\text { Mean } \pm \text { SD }\end{array}$ & $\begin{array}{l}\text { With prior } \\
\text { antibiotic } \\
\text { Mea } \mathbf{n} \pm \text { SD }\end{array}$ & 95\% CI & P value \\
\hline WBC & $267.6(211.3)$ & $208.0(125.3)$ & $-7.711 ; 126.922$ & 0.082 \\
PMNS & $72.9(18.9)$ & $57.14(28.1)$ & $7.048 ; 24.513$ & 0.001 \\
Lymphocytes & $29.4(22.8)$ & $44.4(29.1)$ & $-24.632 ;-5.375$ & 0.003 \\
Protein & $114.1(65.9)$ & $98.3(37.7)$ & $-4.997 ; 36.712$ & 0.135 \\
CSF Sugar & $43.3(11.8)$ & $51.2(13.2)$ & $-12.600 ;-3.305$ & 0.001 \\
Blood sugar & $110.2(17.0)$ & $105(24.4)$ & $-2.422 ; 2.913$ & 0.151 \\
Culture & $3(4.6 \%)$ & $2(4.1 \%)$ & $-0.072 ; 0.083$ & 0.892 \\
positivity & & & & \\
\hline
\end{tabular}

WBC-white blood cells PMNS- polymorphs 
Out of 114 patients of pyogenic meningitis, CSF culture was positive in $5(4.4 \%)$ and blood culture in $6(5.3 \%)$. Organisms included pneumococcus, hemophilus influnzae and enterococcus. Among these children, 2 had been pretreated with antibiotics before lumbar puncture.

\section{Discussion:}

Acute bacterial meningitis is common cause of pediatric admissions with significant mortality and morbidity. We restricted our study to the age group of 1 month to 15 years to focus on the distinct clinical group excluding neonatal meningitis. Early diagnosis, prompt initiation of therapy and supportive care are important for improving the long term outcome. ${ }^{1-3}$ Unfortunately, signs of meningitis cannot be used for making an early diagnosis as evident in the present study. Altered sensorium and convulsions are not universal features. Hence a high index of suspicion is necessary to suspect meningitis and perform a lumbar puncture. In the developing countries with limited resources most children have already received intravenous antibiotics before admission in tertiary care centers. In our cohort of 114 children with bacterial meningitis 49(43\%) had received intravenous antibiotics before the initial lumbar puncture was performed. Numerous previous investigations were done for studying the relationship between antibiotic pretreatment and CSF profiles. There was considerable variation in results regarding effect of antibiotic as evident from previous studies.

A presumptive diagnosis of $\mathrm{ABM}$ is usually possible on the basis of biochemical analysis of CSF. Difficulties arise if patients are already treated with antibiotics as CSF may show normal sugar content and cells may be predominantly lymphocytes. In such cases, one has to rely on other CSF parameters and clinical features. Unfortunately what seems to be difficult especially in our country is accurate bacteriological diagnosis of meningitis. Gram-staining, though a cheap and easy technique can identify organisms at best in $60 \%$ of cases whereas CSF culture results are positive from most western series up to $90 \% .{ }^{1-3}$ There is considerable variation in culture positivity in the study from the developing countries and culture is positive in not more than $15-35 \%$ patients. ${ }^{4,5,16,17}$ Most of studies have shown that antibiotic exposure can render CSF sterile within hours of intravenous medications. ${ }^{7,8}$ In our study only in $4.4 \%$ of cases causative organism was isolated making it difficult for deriving information related to antibiotic effect on CSF cultures. The reasons for low yield of cultures in our study are not clear but may include use of antibiotics prior to hospitalization as evident from previous studies. ${ }^{9-13}$
Poor quality of culture medium and techniques might be other reasons. Alternative quick and sensitive techniques of diagnosis of ABM obviously need to be explored for establishing etiological diagnosis. Of great promise is the CSF latex agglutination test (LAT) which various authors have suggested as simple with superior sensitivity and specificity and unaffected by previous antibiotics therapy. ${ }^{16}$ However some studies show LAT less sensitive compared with gram staining and culture. Role of markers like CSF - CRP, LDH, ADA, serum Procalcitonin and CRP need to be studied for establishing etiological diagnosis of acute bacterial meningitis. ${ }^{15}$

Leukocytosis with neutrophilia was found among the children in both the groups.CRP level was slightly less in children with prior antibiotic therapy.ABM can be associated with hyponatremia secondary to SIADH., ${ }^{9,18}$ Though, mean serum sodium was in lower limit in both the groups none of children had documented symptomatic hyponatremia.

Previous workers found that though cultures were negative CSF parameters are diagnostic of ABM. ${ }^{11,12}$ Another group found that CSF parameters in bacterial meningitis are altered and cause diagnostic dilemma between aseptic and pyogenic meningitis after pretreatment. ${ }^{10}$ One previous study had demonstrated higher CSF sugar level and lower CSF protein level without alteration in CSF white blood cell counts. ${ }^{13} \mathrm{We}$ found that antibiotic pretreatment did not significantly affect CSF WBC count or total CSF protein levels. Though mean CSF sugar was less than $50 \%$ of blood sugar in both the groups, antibiotic pretreatment was associated with higher CSF glucose levels. CSF mean WBC elevated with neutrophilic dominance in both the groups although CSF neutrophils were lower and increased lymphocytes with prior antibiotic therapy. Even if treatment for meningitis is already started these CSF parameters are helpful for the diagnosis of ABM and guide therapy. This emphasizes the importance of lumbar puncture even after days of initiation of intravenous antibiotics. In addition to improvement in cultural techniques, use of clinical scoring system along with use of rapid diagnostic antigenic tests may be helpful in these cases.

There are some important limitations in this present study. First, our study was retrospective and is subject to the limitations of retrospective data gathering. However, we included only objective parameters that were likely to be recorded accurately in the medical records. Second, the CSF finding related to the dose and duration of antibiotic pretreatment could not be defined. The effect of orally administered antibiotics could not be studied as most of the 
data lacked details of prior oral antibiotic therapy. The most important potential limitation was most of CSF gram stain and cultures yielded negative results and non-availability of rapid diagnostic test for establishing etiology of acute bacterial meningitis.

\section{Conclusion:}

It was evident from the current study that antibiotic pretreatment of children with bacterial meningitis affects CSF profiles, specifically resulting higher CSF glucose levels, decrease in neutrophils with increased lymphocytes. High CSF WBC with neutophilic predominance and increased total protein was evident even after pretreatment with intravenous antibiotics.

\section{Acknowledgments:}

We thank all staffs of Medical Record Department of MCOMS, Nepal for assisting in data collection.

\section{Funding: none}

\section{Conflict of interest: none}

\section{References:}

1. Brouwer BM, Tunkel AR, Beek DV. Epidemiology, Diagnosis, and Antimicrobial Treatment of Acute Bacterial Meningitis. Clin Microbiol Rev2010;23:467-94.

2. Sáez-Llorens X, McCracken GH. Bacterial meningitis in children. Lancet 2003;361:2139-48.

3. Bashir HE, Laundy MR. Diagnosis and treatment of bacterial meningitis Arch Dis Child 2003;88:615-20.

4. Ansari I, Pokhrel Y. Culture proven bacterial meningitis in children: agents, clinical profile and outcome. Kathmandu Univ Med J2011;9:36-40.

5. Tiwari KB, Rijal B, Ghimire P. Acute bacterial meningitis in Nepal. Nep Med Coll J2007;9:100-3.

6. WHO. Available at;http://www.nep.searo.who.int/EN/ Index.htm

7. Crosswell JM, Nicholson WR, Lennon DR. Rapid sterilisation of cerebrospinal fluid in meningococcal meningitis: Implications for treatment duration. J Paediatr Child Health2006; 42:170-3.
8. Kanegaye JT, Soliemanzadeh P, Bradley JS. Lumbar Puncture in Pediatric Bacterial Meningitis: Defining the Time Interval for Recovery of Cerebrospinal Fluid Pathogens after Parenteral Antibiotic pretreatment. Pediatrics 2001; 108:1169-74.

9. Prober CG, Dyner LL. Central nervous system infections. In: Kliegman RM, Stanton BF, St.gem JW, eds. Nelson Textbook of Pediatrics. 19 ${ }^{\text {th }}$ ed. 2012. Philadelphia PA: W.B. Saunders; 2088.

10. Converse GM, Gwaltney JM, Strassburg DA, et al. Alteration of cerebrospinal fluid findings by partial treatment of bacterial meningitis. The Journal of Pediatrics. 1973;83:220-5.

11. Winkelstein JA. The influence of partial treatment with penicillin on the diagnosis of bacterial meningitis. The Journal of Pediatrics 1970;77:619-24.

12. Mandal BK. The dilemma of partially treated bacterial meningitis. Scand J Infect Dis 1976;8:185-8.

13. Chapman JL, Bandyopadhyay NK, Dayan P, et al. Effect of Antibiotic Pretreatment on Cerebrospinal Fluid Profiles of Children With Bacterial Meningitis. Pediatrics 2008; 122:726-30.

14. Klein JO, Feigin RD, McCracken GH. Report of the Task Force on Diagnosis and Management of Meningitis. Pediatrics. 1986;78:959-82.

15. Dubos F, Korczowski B, Denizmen A, et al. Serum Procalcitonin Level and Other Biological Markers to Distinguish Between Bacterial and Aseptic Meningitis in Children. Arch Pediatr Adolesc Med 2008;162:115763.

16. Chinchankar N, Mane M, Bhave S, et al. Diagnosis and Outcome of Acute Bacterial Meningitis in Early Childhood. Indian Pediatrics 2002;39:914-21.

17. Thomas V, Riaz A, Qasim S.Cerebro Spinal Fluid Analysis in Childhood Bacterial Meningitis. Oman Med J 2008;23:32-3.

18. Patwari AK, Singh BS, Manorama DE. Inappropriate secretion of antidiuretic hormone in acute bacterial meningitis. Ann Trop Paediatr1995;15:179-83. 